\title{
O SER HUMANO COMO SUJEITO ECOLÓGICO NA VISÃO DOS ALUNOS DO CURSO TÉCNICO EM INFORMÁTICA INTEGRADO AO ENSINO MÉDIO DO IFTM - CAMPUS UBERLÂNDIA
}

Valéria Guimarães de Freitas Nehme ${ }^{1}$ Maria Beatriz Junqueira Bernardes ${ }^{2}$

Resumo: O Instituto Feral do Triângulo Mineiro - Campus Uberlândia - está trabalhando com um projeto de coleta seletiva cujo objetivo é implantar um Programa de Gerenciamento de Resíduos Sólidos em seu campus, contemplando a redução de geração na fonte, a separação dos resíduos recicláveis descartados e a destinação final adequada. Sendo assim, este trabalho tem o objetivo de conhecer a percepção que os estudantes dessa instituição têm acerca de todo esse processo. Será que nossos estudantes percebem a intrincada relação entre consumismo e geração de resíduos? Investigou-se como cada indivíduo pode contribuir com o desafiador processo de redução de resíduos.

Palavras-chave: Resíduos, Percepção Ambiental, Coleta Seletiva.

${ }^{1}$ Instituto Federal do Triângulo Mineiro Câmpus Uberlândia. E-mail: valeria@iftm.edu.br

${ }^{2}$ Universidade Federal de Uberlândia - Instituto de Geografia. E-mail: mbeatriz@ufu.br 


\section{Introdução}

A educação está diretamente ligada à produção de sentidos e valores. Busca-se por meio dela orientar de maneira decisiva as gerações atuais para que estejam preparadas para as incertezas do futuro. Trabalhando com pensamento complexo e aberto às indeterminações, às mudanças, à diversidade, à possibilidade de construir e reconstruir, será possível promover novas leituras e interpretações do mundo, configurando novas possibilidades de ação.

No contexto da educação, a escola aparece como coadjuvante importante no processo ensino-aprendizagem. Destaca-se como o espaço onde são estabelecidas diferentes relações, em que os seres humanos, sujeitos sociais e históricos confrontam saberes.

Conhecer o contexto social dos alunos, as características do grupo como um todo é de fundamental importância para o processo de ensino. A partir delas, o educador trabalhará valores, conceitos, linguagens e atitudes.

À Escola compete, portanto, capacitar o aluno para não apenas "moverse na sociedade", seguindo "o que e como deve sentir e fazer", mas, para ter condições de mover-se, de modificar esse mesmo ambiente, o que só pode acontecer com a ressignificação dos sentidos, com a reconstrução das "normas e regras" prescritas.

Devido à crescente degradação do meio ambiente e à consequente queda na qualidade de vida, nota-se uma preocupação global com o futuro do nosso planeta. Prevalece em nossa sociedade o pensamento de que a natureza pode ser conhecida e conquistada pela metodologia científica, como também, definida de maneira completamente independente do homem e separada dele. Tal postura, assumida pela humanidade, demonstra a falta de conhecimento sobre a importância da conexão entre a sociedade e a natureza.

Leff (2001) afirma que, na história humana, todo conhecimento sobre o mundo e sobre as coisas está condicionado pelo contexto geográfico, ecológico e cultural. Para este autor, a transição para uma sociedade sustentável só será possível se houver investimento na educação, pois a escola é um espaço social, e o que nela se faz, se diz e se valoriza representa um exemplo daquilo que a sociedade deseja e aprova. Dessa forma, considerando a importância da temática ambiental, a escola deverá oferecer meios efetivos para que cada aluno compreenda os fenômenos naturais, as ações humanas e suas consequências para si mesmo, para sua própria espécie, para os outros seres vivos e para o ambiente. Por isso, incluir projetos que enfatizem a temática ambiental nas escolas é de suma importância para que os jovens desenvolvam uma percepção ambiental, que propiciará a busca de soluções para os problemas ambientais locais.

Segundo Tuan (1980), na percepção ambiental da paisagem estão intrínsecos os laços entre o meio ambiente e a visão de mundo do homem. A percepção ambiental é individual e, no processo de interação, há uma 
variedade de elementos que a integram. O autor define a percepção como a resposta dos sentidos aos estímulos externos e como atividade proposital, na qual certos fenômenos são claramente registrados, enquanto outros retrocedem ou são bloqueados. O que percebemos tem valor para nós, para a sobrevivência biológica e para propiciar algumas satisfações que estão enraizadas na cultura.

Sendo assim, este trabalho teve como objetivo identificar as percepções ambientais dos estudantes do curso técnico em informática integrado ao ensino médio e também investigar se eles se percebem como sujeitos ecológicos dentro e fora da instituição de ensino, bem como saber que atitudes adotam no dia-a-dia que demonstram preocupação com meio ambiente.

\section{Educação Ambiental: revendo conceitos}

A Educação Ambiental - por suas origens e configurações diversas transcende o universo escolar. É praticada em vários espaços sociais e políticos: por entidades e organizações governamentais e não governamentais, por instituições de ensino e por empresas. Esta afirmação suscita uma rápida reflexão sobre as questões que envolvem o homem e suas relações com o meio ambiente, objetivando uma convivência equilibrada, consequentemente sustentável.

Conforme as referências dos parâmetros Curriculares Nacionais e da Lei de Diretrizes e Bases da Educação Nacional, a Educação Ambiental na escola tem por objetivo formar cidadãos que se defrontem com a problemática do meio ambiente e se esforcem por compreendê-la, sendo capazes de assumir pontos de vista críticos, preocupando-se com o destino coletivo e se posicionando diante dos desafios do mundo. Nesse contexto, para cidadãos conscientes, tratar de meio ambiente passa a ser uma tarefa inerente ao cotidiano.

A principal função do trabalho com o tema meio ambiente é contribuir para a formação de cidadãos conscientes, aptos a decidir e atuar na realidade socioambiental de modo comprometido com a vida, com o bem-estar de cada um e da sociedade, local e global. Para isso, é necessário que, mais do que informações e conceitos, a escola se proponha a trabalhar com atitudes, com formação de valores, com o ensino e a aprendizagem de habilidades e procedimentos. Esse é um grande desafio para a educação.

Comportamentos "ambientalmente corretos" serão aprendidos na prática do dia-a-dia na escola: gestos de solidariedade, hábitos de higiene pessoal e dos diversos ambientes, participação em pequenas negociações podem ser exemplos disso.

Com base nesses princípios, a adoção de abordagens participativas, por meio de elaboração e execução de projetos educacionais, é fundamental para o soerguimento sociopolítico cultural e ecológico das comunidades locais. A valorização de culturas regionais, a atenção dada a opiniões de pessoas locais 
e o respeito à diversidade de ideias podem ser a chave para um efetivo envolvimento comunitário. Trata-se, em última análise, de uma nova ética com perspectivas de um mundo mais harmônico dependente da instauração de novos valores.

A verdadeira eficiência se traduz na aplicação da educação ambiental em todos os níveis do ensino visando à disseminação de uma cultura estruturada em princípios de equidade social e sustentabilidade ambiental. Informar não é o bastante, porém a tomada de consciência, por meio de práticas de sensibilização e estímulo, mostra-se imprescindível para a transformação de comportamentos e valores. Este pensamento se completa a partir de ações educativas eficazes que induzam a uma ação positiva e conjugada de esforços.

A Educação Ambiental torna-se, a cada dia, um instrumento eficaz para o comprometimento dos cidadãos com a melhoria da qualidade ambiental e da qualidade de vida.

Maturana e Varela (2001) afirmam que o fenômeno de conhecer está diretamente ligado à experiência, e este processo, pelo qual o indivíduo constrói o seu conhecimento, é pessoal, individual e subjetivo. O conhecimento não é somente absorvido da forma em que se apresenta no mundo. A ação ou a experiência ocorrem de maneira circular, dentro da estrutura humana, e o ato de conhecer é que faz surgir um mundo.

A cada dia, estamos cientes de que a manutenção da vida sobre a Terra é um desafio que se impõe à coletividade e não apenas ao ciclo restrito dos governantes e dos servidores públicos. Contribuir para manutenção da qualidade ambiental de nossas comunidades tem se tornado um compromisso dos brasileiros que, gradativamente, vêm incorporando a Educação Ambiental ao elenco de suas preocupações com a própria sobrevivência.

Assim, no contexto atual, a Educação Ambiental emerge como responsabilidade social dos órgãos públicos, das empresas e escolas como um campo de estudos, vivência e ações voltadas para a criação de condições indispensáveis para que os homens e as comunidades sejam estimulados a contribuir para melhoria de suas condições de vida.

A Educação Ambiental aponta para reflexões sobre a práxis social, que é o processo de (re)construção e movimento da sociedade fundamentada em valores, no sentido econômico e na dinâmica do trabalho. Trata-se de uma situação complexa, pois os valores estão cada vez arraigados no consumo e na acumulação do capital. Para que a Educação Ambiental desempenhe o seu papel é necessário que ocorra uma mudança na cultura associada a transformações sociais e econômicas 


\section{Resíduos sólidos: da geração ao tratamento e impactos na saúde}

A produção de resíduos sólidos faz parte do cotidiano do ser humano. Não se pode imaginar um modo de vida que não gere resíduos sólidos. Devido ao aumento da população humana e à concentração dessa população em centros urbanos, são nítidos os problemas causados pela crescente produção de resíduos sólidos. Isso tem como principal explicação, o modo de vida baseado na produção e no consumo.

Resíduo pode ser definido como o material que não tem mais valor econômico para seu possuidor, ou ainda é simplesmente tratado como "lixo" para a maioria das sociedades. A Associação Brasileira de Normas Técnicas (ABNT, 1987), considera resíduos sólidos como:

[...] resíduos no estado sólido e semi-sólido, que resultam de atividade da comunidade de origem: industrial, doméstica, comercial, agrícola, de serviços de varrição. Incluem-se também os lodos provenientes dos sistemas de tratamento de água, bem como determinados líquidos cujas particularidades tornem inviável o lançamento na rede pública de esgotos ou corpos de água, ou que exijam para isso soluções técnicas e econômicas inviáveis.

De qualquer modo, os resíduos constituem-se como subprodutos das atividades humanas, com características específicas, definidas geralmente pelo processo que os gerou. Os materiais que são descartados, mas ainda podem ter alguma utilidade, deixam de ser resíduos e tornam-se matérias-primas secundárias. Por último, existem os rejeitos, que equivalem a todos os resíduos que não têm aproveitamento econômico por nenhum processo tecnológico disponível.

Segundo Phillippi Jr; Aguiar (2005), os resíduos sólidos são classificados de acordo com sua origem, sendo que os principais tipos são: domiciliares, industriais, comerciais, serviços de saúde, serviços de transporte, sólidos de construção civil. Independentemente de sua origem, devem passar por uma série de operações para que tenham manejo e destinos ambientais e sanitários seguros.

Quando manejados inadequadamente, o "lixo" oferece alimento e abrigo para muitos vetores de doenças, especialmente roedores como ratos, e insetos como moscas, baratas e mosquitos. Atualmente está bastante esclarecida a relação entre a proliferação de certas doenças e o manejo inadequado de resíduos sólidos.

O sistema de gerenciamento de resíduos sólidos em ambiente urbano envolve uma série de atividades, desde o acondicionamento e armazenamento, serviços de coleta e transporte, até o tratamento e a disposição final. 
Para tanto, o tratamento dos resíduos sólidos procura modificar suas características como quantidade, toxidade e patogenia, de forma a diminuir os impactos sobre o ambiente e a saúde pública. E, as alternativas tecnológicas são aplicadas de acordo com as características particulares da composição dos resíduos, do município ou região e dos recursos disponíveis.

No caso dos resíduos sólidos domiciliares, compostos principalmente por vidros, plásticos e matéria orgânica, a maioria dos municípios brasileiros, destina-os à aterros adequados ou não, sem tratamento prévio. Sobre isso, sabe-se que existem diversas iniciativas de reciclagem, de compostagem e de outras medidas que, por enquanto, ainda representam uma quantidade pouco significativa de tratamento destes resíduos.

Para os resíduos industriais, comerciais, de serviços de saúde e de construção civil, o melhor destino dado a eles envolve um gerenciamento integrado. Esse tipo de gerenciamento consiste na prática de utilizar diversas alternativas para solucionar o problema dos resíduos sólidos, de tal forma que o conjunto tenha sustentabilidade econômica, ambiental e social.

De acordo com Phillippi Jr. (2005), a forma mais comum de abordar esse sistema integrado, inclui mudanças de padrão de consumo e a prática de priorizar os "3 $R s$ ", e para alguns autores existe ainda um quarto " $R$ ", que juntos significam: Reduzir, Reutilizar, Reciclar, e Recuperar. Essas medidas colaboram para diminuir a geração de resíduos, e a minimização de seus rejeitos, por meio da reutilização, da reciclagem e da recuperação destes subprodutos.

É importante destacar que os resíduos oriundos de serviços de saúde, devem receber um tratamento especial, já que apresentam um elevado potencial de contaminação por agentes patogênicos. Nesse sentido, os mesmos devem ser devidamente acondicionados, a coleta deve ser realizada frequentemente e, o tratamento precisa ser feito de acordo com suas características. Os resíduos patogênicos também necessitam de um tratamento que vise à eliminação dos micro-organismos causadores de doenças (tratamentos como incineração, autoclavagem, micro-ondas, aplicação de cal e desinfecção química).

Além de tudo isso, é importante destacar que a decomposição dos resíduos e a formação de lixiviados podem levar à contaminação do solo e de águas subterrâneas com substâncias orgânicas, micro-organismos patogênicos e inúmeros contaminantes químicos presentes nos diversos tipos de resíduos.

Desse modo, entende-se que a questão do "lixo" é um dos problemas urbanos de maior preocupação para os órgãos gestores municipais, estaduais e federais, já que envolvem políticas públicas voltadas para o saneamento do meio, vigilância em saúde ambiental e vigilância epidemiológica, ou seja, medidas de saúde pública. 


\section{Material e Métodos}

A pesquisa foi realizada com 50 alunos do curso técnico em informática integrado ao ensino médio do Instituto Federal do Triângulo Mineiro - Campus Uberlândia, MG. A metodologia de pesquisa é qualitativa, com a definição da amostra por conveniência.

\section{Resultados e Discussão}

Dos 50 sujeitos pesquisados, 12 (24\%) são do sexo feminino e 38 (76\%) do sexo masculino. Em relação à faixa etária, os estudantes possuem entre 14 e 18 anos, sendo 5 (10\%) com 14 anos; 25 (50\%) com 15 anos; 8 (16\%) com 16 anos; 11 (22\%) com 17 e apenas 1 (2\%) com idade de 18 anos. Nota-se que os alunos se encontram dentro da faixa etária apropriada para cursar 0 ensino médio. A pesquisa é de caráter quantitativo e utilizou-se como instrumento de medida um questionário semiestruturado composto por seis questões.

As respostas expressam as percepções dos adolescentes a cerca do meio ambiente. Sauvé (1997) classifica a concepção de meio ambiente em seis categorias: como natureza, como um recurso, como um problema, como um lugar para se viver, como biosfera e como um projeto comunitário. (SAUVÉ, 1997).

Dessa forma, baseando-se nessas categorias, quando questionados sobre o que é meio ambiente, 24 alunos (48\%) apresentam uma concepção de meio ambiente como local em que vivemos e também como um conjunto de tudo o que está a nossa volta, ou seja, têm uma visão em que não se enfocam aspectos ecológicos, ou seja, o homem é excluído deste conceito. Esta visão demonstra que existe uma carência de conhecimento sobre a introdução do homem no que chamamos de meio. Ressaltando o que afirma Quintas (1995) "o homem pensa e age como se estivesse fora da natureza". As demais concepções podem ser visualizadas na tabela 1 :

Tabela : O que é meio ambiente?

\begin{tabular}{l|c|c}
\hline Respostas & Ocorrências & $\%$ \\
\hline Local em que vivemos & 24 & $48 \%$ \\
\hline Conjunto de seres vivos, natureza e vida & 15 & $30 \%$ \\
\hline Tudo o que está a nossa volta & 5 & $10 \%$ \\
\hline Tudo aquilo que podemos ver ou sentir & 1 & $2 \%$ \\
\hline O que faz o mundo sobreviver & 1 & $2 \%$ \\
\hline As praças, ruas, escolas e outros & 1 & $2 \%$ \\
\hline Tudo & 1 & $2 \%$ \\
\hline As coisas boas do mundo & 1 & $2 \%$ \\
\hline Não Respondeu & 1 & $2 \%$ \\
\hline Total & 50 & $100 \%$ \\
\hline
\end{tabular}

Fonte: Trabalho de campo realizado em 21/09/2011. 
O meio ambiente, portanto, deve ser compreendido como tudo o que cerca o ser vivo exercendo influência sobre ele, além disso, é indispensável a sua sustentação. Nele incluem solo, clima, recursos hídricos, ar, nutrientes e os outros organismos. É constituído pelo meio físico e biológico e também pelo meio sociocultural e pela sua relação com os modelos de desenvolvimento adotados pela sociedade.

A outra questão diz respeito ao projeto de coleta seletiva realizado no IFTM - Campus Uberlândia. Indagamos se o aluno saberia relacionar quais benefícios esse projeto nos proporcionaria. As respostas (tabela 2) demonstram que os alunos reconhecem a importância de acondicionar o lixo nos locais corretos, pois apreciam ambientes limpos. A reciclagem foi apontada com maior número de citação (30\%). Esse resultado demonstra o interesse dos alunos em participar do projeto. No entanto, não devemos nos esquecer de que mais importante do reciclar é necessário reduzir o consumo.

Tabela 2: Benefícios da coleta seletiva no ambiente escolar.

\begin{tabular}{l|c|c}
\hline Respostas & Ocorrências & $\%$ \\
\hline Reciclagem & 15 & $30 \%$ \\
\hline Ter um ambiente limpo & 11 & $22 \%$ \\
\hline Não sabem & 11 & $22 \%$ \\
\hline Melhorar a qualidade de vida & 3 & $6 \%$ \\
\hline Reduzir a produção de lixo & 3 & $6 \%$ \\
\hline Jogar o lixo no local correto & 3 & $6 \%$ \\
\hline Não Respondeu & 3 & $6 \%$ \\
\hline Melhorar o lixo & 1 & $2 \%$ \\
\hline Total & 50 & $100 \%$ \\
\hline
\end{tabular}

Fonte: Trabalho de campo realizado em 21/09/2011.

A terceira questão investiga as ações que praticadas pelos sujeitos pesquisados demonstram preocupação com o meio ambiente (tabela 3).

Tabela 3: O que você faz de concreto que demonstra sua preocupação com o meio ambiente?

\begin{tabular}{l|c|c}
\hline Respostas & Ocorrências & $\%$ \\
\hline Jogar lixo no lixo & 22 & $51 \%$ \\
\hline Coleta Seletiva & 12 & $28 \%$ \\
\hline Reduzir o consumo de água & 5 & $12 \%$ \\
\hline Não poluir o meio ambiente & 2 & $5 \%$ \\
\hline Nada & 2 & $5 \%$ \\
\hline Total & 43 & $86 \%$ \\
\hline
\end{tabular}

Fonte: Trabalho de campo realizado em 21/09/2011. 
Foi possível constatar, por meio das respostas a aquisição, de novos valores e atitudes, por parte dos estudantes. Vinte e dois alunos $(51 \%)$ jogam o lixo no lugar adequado. É significativa também a quantidade de alunos que afirmam realizar a coleta seletiva (28\%) e também reduzir o consumo de água (12\%). No entanto, dois alunos, (5\%) responderam que não 'fazem nada porque o meio ambiente onde vivem não proporciona nenhum incentivo'. Segundo eles, a maior parte das pessoas não demonstra nenhum interesse.

$\mathrm{Na}$ quarta questão, os alunos foram solicitados a sugerir ações que contribuem para reduzirmos a quantidade de lixo que produzimos (tabela 4).

Tabela 4: Que sugestões você daria para reduzirmos a quantidade de lixo que produzimos?

\begin{tabular}{l|c|c}
\hline Respostas & Ocorrências & $\%$ \\
\hline 3Rs (Reduzir, Reutilizar, e Reciclar) & 20 & $40 \%$ \\
\hline Autoconsciência & 16 & $32 \%$ \\
\hline Coleta Seletiva & 6 & $12 \%$ \\
\hline Consumir apenas o necessário & 3 & $6 \%$ \\
\hline Compostagem & 1 & $2 \%$ \\
\hline Economizar & 1 & $2 \%$ \\
\hline Combater o aquecimento global & 1 & $2 \%$ \\
\hline Não sabem & 2 & $4 \%$ \\
\hline Total & 50 & $100 \%$ \\
\hline
\end{tabular}

Fonte: Trabalho de campo realizado em 21/09/2011.

Os estudantes demonstram claramente que os estudantes foram motivados a participar do projeto de coleta seletiva no campus Uberlândia, pois $20(40 \%)$ citaram a pedagogia dos 3 Rs. Alguns já se encontram em um nível interessante de tomada de consciência, pois declaram que devemos consumir somente o necessário.

\section{Considerações Finais}

Os sujeitos dessa pesquisa são estudantes do curso técnico em informática integrado ao ensino médio do Instituto Federal do Triângulo Mineiro - Campus Uberlândia, MG, portanto já concluíram o Ensino Fundamental, e estão em busca de uma complementação dos conhecimentos já obtidos e também de inserção no mercado de trabalho. No decorrer da discussão e por meio das respostas obtidas, ficou evidente que o conceito de Meio Ambiente não está bem definido para alguns estudantes, melhor dizendo limita-se aos aspectos naturais. No entanto, com relação ao significado dele para a sua vida demonstraram o seu real papel e o que fazem de concreto demonstra preocupação com ele, apesar de serem ações ainda pouco abrangentes.

A complexidade ambiental envolve múltiplas dimensões e, portanto, a Educação Ambiental precisa ser trabalhada de forma interativa com as mais variadas áreas do conhecimento. Um dos seus objetivos é desenvolver uma compreensão integrada do meio ambiente em suas múltiplas e complexas 
relações envolvendo aspectos ecológicos, psicológicos, legais, políticos, sociais, econômicos, científicos, culturais e éticos, ou seja o incentivo à participação individual e coletiva na preservação do equilíbrio do ambiente, nesse sentido a defesa da qualidade de vida está diretamente ligada ao exercício da cidadania.

O grande desafio então é estabelecer novo pacto para construir a cultura ecológica, ou seja, buscar a compreensão da natureza e sociedade como dimensões inter-relacionadas. A educação ambiental destaca-se, então como uma necessidade urgente, que deve possibilitar ao estudante assumir posições diante dos problemas que surgem em seu espaço de vivência, e levá-lo à tomada de consciência com relação às responsabilidades sociais, para que tenha subsídios para efetuar as mudanças necessárias na sociedade da qual faz parte.

As diferentes condições vivenciadas pela população, como a destruição de ecossistemas, a contaminação crescente da atmosfera, solo e água, bem como o aquecimento global são alguns exemplos de impactos decorrentes das ações humanas sobre 0 ambiente, são riscos advindos de processos produtivos passados e presentes, como a disposição inadequada de resíduos industriais, a contaminação de mananciais de água e as más condições de trabalho e moradia. Esse conjunto de fatores configura-se como riscos à saúde advindos de condições ambientais adversas.

O saber ambiental é a alternativa à crise, o reconhecimento da complexidade que envolve as relações entre sociedade e ambiente (LEFF, 2002). Educação Ambiental, nesse contexto, a desempenha importante papel como articuladora de todos os seguimentos da sociedade, pois ela é uma filosofia de educação que perpassa por todas as áreas conhecimento e exige reflexões acerca da problemática ambiental e também acerca da educação. Novos valores e atitudes devem ser adotados para despertar, em cada indivíduo, o sentimento de pertencimento, participação, solidariedade e responsabilidade na busca de respostas locais e globais para a crise que enfrentamos.

\section{REFERÊNCIAS}

ALVES, L. R. G; PRETO, N. Escola: um espaço de aprendizagem sem prazer? In: Comunicação e Educação. Vol. 2. № 16, 1999.

CORTELLA, M.S. A escola e o conhecimento. São Paulo: Cortez, 2002.

DAYRELL, J. Múltiplos olhares sobre educação e cultura. Belo Horizonte: UFMG, 1996.

DIAS, G. F. Educação ambiental: princípios e práticas. São Paulo: Gaia, 1994. 
GONÇALVES, C. W. P. Os (des)caminhos do meio ambiente. 10 ed. São Paulo: Contexto, 202.

LEFF, E. Saber ambiental: sustentabilidade, racionalidade, complexidade, poder. Petrópolis: Vozes, 2002.

LOUREIRO, C. F. B., LAYRARGUES, P. P. , CASTRO, S. de C. (orgs) Educação ambiental: repensando o espaço da cidadania. 2 ed. São Paulo: Cortez, 2002.

LAYARGUES, P. O cinismo da reciclagem: o significado ideológico da reciclagem da lata de alumínio e suas implicações para a educação ambiental. LOUREIRO, F.; LAYARGUES, P.; CASTRO, R. (Orgs.) Educação ambiental: repensando o espaço da cidadania. São Paulo: Cortez, 2002, 179-220.

MATURANA, H. R. e VARELA, F. J. A árvore do conhecimento: as bases biológicas da compreensão humana. São Paulo: Palas Athena, 2001.

PHILLIPPI, JR; AGUIAR, A. de O. Resíduos sólidos:. In: PHILIPPI JR., Arlindo. Saneamento, Saúde e Meio . p 267.

SAUVÉ, L. Educação Ambiental e Desenvolvimento: uma análise complexa. Revista de Educação Pública 6 (1): p.23, 1997.

TUAN, Yi-fu. Topofilia: um estudo da percepção, atitudes e valores do meio ambiente. São Paulo: Difel, 1980. 